\title{
LINGUISTIC AND PRAGMATIC COMPETENCE: DEVELOPMENT ISSUES
}

\author{
Leyla Hasbún Hasbún
}

\begin{abstract}
RESUMEN
El presente es un estudio del desarrollo lingüístico y pragmático de un grupo de estudiantes de inglés como lengua extranjera quienes escribieron una serie de mensajes a sus profesores. La evaluación de este desarrollo, la cual se espera se refleje en los mensajes, fue llevada a cabo por un grupo de profesores, un grupo de estudiantes hablantes nativos del inglés y dos grupos de estudiantes de la Escuela de Lenguas Modernas. Los resultados indican que hay diferencias entre las apreciaciones entre los grupos y dentro del mismo grupo; que las justificaciones empleadas varían en el grado de elaboración, y que los estudiantes juzgaron que algunas formas gramaticales eran incorrectas.
\end{abstract}

\begin{abstract}
This is a study of the linguistic and pragmatic development of a group of students of English as a foreign language who wrote a series of messages to their professors. A group of professors and a group of students who are native speakers of English, as well as two groups of EFL students at the School of Modern Languages, all evaluated this development by judging the accuracy and the appropriateness of the messages. Results indicate that there is a difference of opinion among groups and within groups, that the justifications provided vary in their degree of elaboration, and that the EFL students identified as errors structures that were actually grammatical.
\end{abstract}

\section{Introduction}

Due to the arrival of multinational companies in the last few decades, there has been a dramatic increase in the amount of communication between individuals of different linguistic and cultural backgrounds in the workplace in Costa Rica. Pervasive economic pressures have made the government and the institutions of higher education realize that more extensive and better quality foreign language education is required in our country if we are to compete successfully in the global marketplace. Obviously, the degrees of bilingualism and the particular communication skills required in specific jobs are different. However, the consensus of opinion seems to be that there is a widespread need for true communicative competence.

Although the notion of communicative competence goes back to Hymes (1972), Canale and Swain (1980) and Canale (1983) have proposed the most influential model. It comprises four competencies: grammatical, sociolinguistic, discourse, and strategic competence. More recently, there have been several reformulations of the components. One of 
them was proposed by Bachman (1990), who adds pragmatic competence. This new component incorporates illocutionary and sociolinguistic competence. The former is the ability to match the meaning of an utterance with its pragmatic force as well as the ability to understand functional aspects of the language. The latter refers to culturally related aspects of the language such as politeness or formality.

Pragmatic competence is indispensable in face-to-face interactions in a foreign language. Children acquire pragmatic competence in their native language through interaction with their caretakers or older children, in other words, engagement in contextualized communicative activities. They receive continuous feedback from parents and peers who model appropriate routines, establish rules, and "correct" children's inappropriate behavior. This feedback contributes to the acquisition of the pragmatic skills required to function in their community. In contrast, most adult foreign language learners lack that type of input. Consequently, the classroom becomes the most important, and perhaps the only, source of relevant input for the development of their pragmatic competence. (See Kim and Kelly Hall, 2002 for a discussion of this problem.) Kasper and Schmidt (1996: 160) claim that adult learners require explicit instruction. Otherwise, they will experience "difficulty in acquiring appropriate language use patterns, especially in foreign language or classroom settings where opportunities for the full range of human interactions is limited." Thus, language programs must provide ample opportunities to develop those skills. Nelson et al. (2002: 164) summarize some of the negative consequences of lacking pragmatic competence as follows:

\footnotetext{
The importance of pragmatic competence has been demonstrated by numerous researchers (...) whose work reveals that while native speakers often forgive the phonological, syntactic, and lexical errors made by L2 speakers, they are less likely to forgive pragmatic errors. Native speakers typically interpret pragmatic errors negatively as arrogance, impatience, rudeness, and so forth. Furthermore, pragmatic errors can lead to a listener's being unable to assign a confident interpretation to a learner's utterance.
}

In a recent study, Kasper (2001: 506) identifies four general theoretical approaches that have been adopted to account for pragmatic development in second and foreign language learners: a comprehensive model of communicative competence, information processing hypotheses, sociocultural theory and language socialization theory. The focus of the present study is the first option. Kasper explains that under this approach pragmatics has been examined either as an independent component of the model or as one that interacts with grammatical competence, that is, mastering the linguistic code. In the latter type of studies she has found the following:

\footnotetext{
Studies examining the relationship between pragmalinguistic and grammatical ability report two sets of outcomes. One group of results documents that learners acquire an L2 grammatical feature before they acquire its pragmalinguistic functions. The other set of findings indicates that learners use L2 pragmatic functions before they acquire the L2 grammatical forms that are acceptable realizations of those functions.
}

In an important study which is an example of the first group of investigations reviewed by Kasper (2001), Bardovi-Harlig and Dörnyei (1998) studied ESL and EFL learners' pragmatic and grammatical awareness. Using an error recognition and severity rating task, they found that whereas EFL learners and their teachers consistently ranked grammatical errors as more serious than pragmatic errors, the opposite pattern was observed in ESL learners and their teachers. 
In a recent investigation, Hasbún (2001) explored the relationship between grammatical competence, which is understood as accuracy of structure, and pragmatic competence, that is, the appropriateness of utterances according to specific situations, speakers and content. A group of messages written by university level learners of English as a foreign language were used to develop a grammatical and pragmatic judgment task. The objectives of the study were to determine if messages judged as accurate are also considered appropriate and vice versa, whether NSs and NNs rate the severity of a given problem in the same way, and if teachers who are NSs are harsher or more lenient in their judgments than teachers who are NNs. Results showed that for the most part $(79 \%$ of the messages), judges gave similar accuracy and appropriateness scores to the messages. In other words, there was a tendency to rate accurate messages as appropriate and inaccurate messages as inappropriate. This suggests that the students' grammatical and pragmatic development are parallel. Second, the scores produced by NS and NNS teachers of English were similar: $73.7 \%$ of the messages received the same score, whether positive or negative, from both groups. However, NNS teachers were usually stricter in both accuracy and appropriateness than teachers who were NS of English. NNS teachers gave $68.4 \%$ of the messages lower scores in the area of accuracy, and $63.1 \%$ of the messages lower scores in appropriateness.

The purpose of the present investigation is to have other groups of subjects rate the messages in Hasbún (2001) to answer the following questions:

1. Do the different groups of subjects rate grammatical and pragmatic violations in the same way? Is there a general consensus as to what constitutes a violation?

2. When rating the messages, do the EFL learners justify their scores by using arguments similar to those given by the US students and the EFL teachers?

3. Do EFL learners misidentify errors or violations?

\section{Methodology}

\subsection{Participants}

The present investigation was conducted in the School of Modern Languages at the University of Costa Rica. Four groups of subjects participated as judges: 43 second year EFL students and 30 fourth year EFL students, 10 US college students, all of whom are native speakers of English, and 16 professors who teach English language and literature. Of those 16 professors, 4 are native speakers of English, and 12 are native speakers of Spanish.

The Costa Rican EFL students had varying degrees of both language proficiency and exposure to conversational English outside the classroom. They were included in the study because it is crucial to determine whether the activities and materials used in our classrooms provide learners with the pragmatic input needed for target-like grammatical and pragmatic judgments. In addition, it was important to see how accuracy and proficiency develop in a university setting. 
Finally, the group of learners who wrote the messages analyzed in the present study are described in detail in Hasbún (2001).

\subsection{The Data}

The data used consisted of five electronic mail messages and fourteen notes that EFL college learners had sent to their professors. These students were from Costa Rica, Colombia and Panama, and their native language was Spanish. The addressees were three professors, two females and one male. The messages used met two requirements: they were written in English, the subjects' L2, and the purpose of the message was either to apologize or to make a request. These two speech acts were selected because of the degree of imposition involved. By their very nature, they are likely to be face threatening in any language. The following table describes the content of the messages.

Table 1

Speech Act Performed in Each Message and Description of the Context

\begin{tabular}{|c|c|c|}
\hline Message number & Speech Act & Context \\
\hline \multirow[t]{2}{*}{1} & Apology & Electronic message was accidentally sent still unfinished \\
\hline & Request & Arrange an appointment \\
\hline 2 & Request & Acknowledge the receipt of an evaluation form by calling student \\
\hline \multirow[t]{2}{*}{3} & Apology & Not having handed in paper \\
\hline & Request & Accept a late paper \\
\hline 4 & Request & Read a draft of a paper and give feedback \\
\hline 5 & Apology & Being absent from class \\
\hline \multirow[t]{2}{*}{6} & Apology & Missing an appointment \\
\hline & Request & Arrange a new appointment \\
\hline 7 & Apology & Being absent from class \\
\hline 8 & Apology & Not turning in an assignment on time \\
\hline \multirow[t]{2}{*}{9} & Apology & Dropping out of a class without first talking to the professor \\
\hline & Request & Return a cassette \\
\hline 10 & Apology & Being absent from class \\
\hline 11 & Request & Provide feedback on a project \\
\hline 12 & Request & Sign a document and take it to the Main Office \\
\hline 13 & Request & Give an additional assignment to improve a grade \\
\hline 14 & Request & Acknowledge the receipt of a paper by calling or e-mailing student \\
\hline \multirow[t]{2}{*}{15} & Request & Acknowledge the receipt of a paper by e-mailing student \\
\hline & Request & Give student a higher grade \\
\hline 16 & Request & Accept a handwritten paper \\
\hline \multirow[t]{2}{*}{17} & Apology & Being absent from class \\
\hline & Request & Give a makeup exam \\
\hline 18 & Apology & Being absent from class and submitting a paper electronically \\
\hline 19 & Request & Fill out an inventory form for a class project \\
\hline
\end{tabular}


Another important reason why this set of data was chosen is the need for "more authentic data, collected in the full context of the speech event" as Kasper and Dahl (1991: $245)$ recommend when doing research in the field of interlanguage pragmatics.

\subsection{The Instrument}

To obtain the subjects' scores of the messages, the author developed a pragmatic and grammatical judgment task. To make sure the subjects understood what they were intended to do, instructions provided contextualized examples of the concepts of "accuracy" and "appropriateness" used by Bardovi-Harlig and Dörnyei (1998: 241). They were asked to rate each of the 19 messages in terms of accuracy and appropriateness using the following descriptors: very good, good, borderline, needs work and poor. Moreover, they were requested to justify their choices whenever the scores were "borderline" or below. For an abbreviated version of the instrument, see Hasbún (2001).

\subsection{Procedure}

In order to compare the scores given by the four groups of subjects, numeric values were assigned to the four possible descriptors as follows: very good 2, good 1, borderline 0 , needs work -1 , and poor -2 . Then, the mean scores and standard deviations were calculated. Next, the difference between groups was estimated. Finally, the in-group differences between the accuracy and the appropriateness scores given to each message were computed.

\section{Results and Discussion}

\subsection{Do the different groups of subjects rate grammatical and pragmatic violations in the same way? Is there a general consensus as to what constitutes a violation?}

Table 2 summarizes the judgments made by the four groups of participants in the area of accuracy. It includes the mean score for each of the 19 messages received from the 4 groups of subjects as well as the standard deviations.

Two preliminary conclusions can be drawn from Table 2 . The first one is that there is an obvious difference in the accuracy scores among groups. This difference will be discussed in greater detail in Table 4. The second conclusion is that the standard deviations indicate that there is a degree of variability among the members of the same group. It is important to remember that the possible scores range from 2 to -2 , and that a difference of 1 point represents a significant change in descriptor. For example, it might mean going from "good" to "borderline" or from "needs work" to "poor."

Differences of more than one full point occurred in $15.8 \%$ of the messages evaluated by the professors, in $21 \%$ of the messages judged by the US students, in $52.6 \%$ of the messages read by the fourth year students and in $26.3 \%$ of the messages rated by the second 
Table 2

Mean Scores and Standard Deviations by Group: Accuracy

\begin{tabular}{|c|c|c|c|c|c|c|c|c|}
\hline \multirow[t]{2}{*}{ Message } & \multicolumn{2}{|c|}{$\begin{array}{c}\text { Professors } \\
n=16\end{array}$} & \multicolumn{2}{|c|}{$\begin{array}{c}\text { NS Students } \\
n=104^{\text {th }}\end{array}$} & \multicolumn{2}{|c|}{$\begin{array}{l}\text { Year Students } \\
n=302^{\text {nd }}\end{array}$} & \multicolumn{2}{|c|}{$\begin{array}{c}\text { Year Students } \\
\mathbf{n}=\mathbf{4 3}\end{array}$} \\
\hline & Mean & S.D. & Mean & S.D. & Mean & S.D. & Mean & S.D. \\
\hline 1 & -1.81 & 0.54 & -1.50 & 0.97 & -1.79 & 0.40 & -0.74 & 1.02 \\
\hline 2 & 0.12 & 0.62 & 0.30 & 0.67 & 0.93 & 1.14 & 1.16 & 0.92 \\
\hline 3 & 0.62 & 0.96 & 1.10 & 0.57 & 1.00 & 1.02 & 1.09 & 0.89 \\
\hline 4 & 0.75 & 1.12 & 0.70 & 0.82 & 0.52 & 1.00 & 0.88 & 1.03 \\
\hline 5 & -0.25 & 0.77 & 0.10 & 0.74 & -0.52 & 1.00 & 0.00 & 0.84 \\
\hline 6 & 0.00 & 1.03 & 0.30 & 1.06 & -0.35 & 1.01 & 0.08 & 0.96 \\
\hline 7 & -0.94 & 0.85 & -0.44 & 1.16 & -1.07 & 1.14 & -0.50 & 1.20 \\
\hline 8 & 0.87 & 1.02 & 1.30 & 0.95 & 1.27 & 0.78 & 1.53 & 0.70 \\
\hline 9 & -1.5 & 0.73 & -1.12 & 0.73 & -0.86 & 1.33 & 0.15 & 1.19 \\
\hline 10 & 0.27 & 0.85 & 0.90 & 0.87 & 0.53 & 0.97 & 1.17 & 0.75 \\
\hline 11 & 1.31 & 0.60 & 1.00 & 1.25 & 0.90 & 0.80 & 0.93 & 0.88 \\
\hline 12 & 1.20 & 0.40 & 0.40 & 0.70 & 0.30 & 1.04 & 0.58 & 0.79 \\
\hline 13 & 0.27 & 0.68 & 0.67 & 0.94 & 1.44 & 0.61 & 1.42 & 0.70 \\
\hline 14 & -1.62 & 0.62 & -0.90 & 0.99 & -1.45 & 0.89 & -0.62 & 1.21 \\
\hline 15 & -1.75 & 0.45 & -1.10 & 0.87 & -0.79 & 1.14 & 0.46 & 0.81 \\
\hline 16 & -0.62 & 0.81 & -0.33 & 1.25 & 0.25 & 1.04 & 0.63 & 0.99 \\
\hline 17 & 1.44 & 0.51 & 0.90 & 0.99 & 1.15 & 0.73 & 1.16 & 0.61 \\
\hline 18 & 1.19 & 0.75 & 0.90 & 0.74 & 0.64 & 0.92 & 0.95 & 0.61 \\
\hline 19 & 1.33 & 0.60 & 1.20 & 0.63 & 0.82 & 0.98 & 0.89 & 0.68 \\
\hline
\end{tabular}

Very $\operatorname{good}=2 \quad$ Good $=1 \quad$ Borderline $=0 \quad$ Needs work=-1 $\quad$ Poor=-2

year students. The group comprised of instructors shows the least variability in judgment, followed by the US college students. As to the EFL learners, the fourth year students showed much more variability than any other group. What this situation seems to indicate is that the more advanced students are aware of grammatical errors, and that at least some of them become more critical or even hypercritical. On the other hand, the second year students probably lack the linguistic competence necessary to detect some of the errors and, therefore, tend to assign higher scores more uniformly.

Table 3 summarizes the average scores and standard deviations for the 19 messages in the area of appropriateness.

Once again, there is a difference in scores among groups, which will be dealt with in Table 5. In addition, the standard deviations indicate that there are also in-group differences in the appropriateness scores. Discrepancies of more than one full point occurred in $47.4 \%$ of the messages for the professors, in $57.9 \%$ for the US students, in $84.2 \%$ or the fourth year students, and in $47.4 \%$ for the second year students. Although the same pattern was observed when the accuracy scores were analyzed, the variability in the appropriateness scores is higher. These results are not surprising. While the grammar of English has been described thoroughly within different frameworks, and the grammaticality of an utterance can be checked against a grammar book or the intuitions of a native speaker, pragmatic rules are more elusive and are seldom explicitly taught. Furthermore, those rules vary considerably depending on the context. 
Table 3

Mean Scores and Standard Deviations by Group: Appropriateness

\begin{tabular}{|c|c|c|c|c|c|c|c|c|}
\hline \multirow[t]{2}{*}{ Message } & \multicolumn{2}{|c|}{$\begin{array}{c}\text { Professors } \\
n=16\end{array}$} & \multicolumn{2}{|c|}{$\begin{array}{l}\text { NS Students } \\
n=104^{\text {th }}\end{array}$} & \multicolumn{2}{|c|}{$\begin{array}{c}\text { Year Students } \\
n=302^{\text {nd }}\end{array}$} & \multicolumn{2}{|c|}{$\begin{array}{c}\text { Year Students } \\
n=43\end{array}$} \\
\hline & Mean & S.D. & Mean & S.D. & Mean & S.D. & Mean & S.D. \\
\hline 1 & -0.19 & 0.91 & -0.50 & 1.51 & -0.81 & 1.08 & -0.38 & 0.94 \\
\hline 2 & 0.69 & 0.87 & 0.90 & 0.99 & 0.77 & 1.19 & 1.00 & 0.72 \\
\hline 3 & 0.69 & 1.14 & -0.60 & 1.65 & 0.37 & 1.03 & 0.80 & 1.07 \\
\hline 4 & -0.44 & 1.03 & 0.00 & 1.41 & 0.07 & 1.20 & 0.33 & 1.01 \\
\hline 5 & 0.31 & 0.87 & 0.60 & 1.07 & 0.53 & 1.07 & 0.35 & 0.89 \\
\hline 6 & 0.25 & 1.00 & 0.90 & 0.99 & 0.00 & 1.31 & 0.66 & 0.99 \\
\hline 7 & -0.31 & 1.08 & -0.33 & 1.41 & -0.86 & 1.07 & -0.90 & 1.36 \\
\hline 8 & 1.06 & 0.57 & 1.60 & 0.52 & 1.45 & 0.67 & 1.58 & 0.62 \\
\hline 9 & 0.37 & 1.36 & 0.00 & 1.33 & -0.27 & 1.34 & 0.36 & 1.29 \\
\hline 10 & 0.37 & 0.88 & 1.40 & 0.52 & 0.65 & 1.03 & 1.05 & 0.90 \\
\hline 11 & -0.25 & 1.29 & 0.00 & 1.33 & 0.14 & 1.07 & 0.44 & 0.90 \\
\hline 12 & 0.67 & 0.87 & 0.25 & 0.62 & -0.59 & 1.10 & -0.05 & 1.23 \\
\hline 13 & 0.06 & 0.85 & 0.70 & 0.67 & 1.14 & 1.17 & 1.45 & 0.79 \\
\hline 14 & -0.75 & 1.24 & -0.90 & 1.10 & -1.07 & 1.01 & -0.50 & 1.11 \\
\hline 15 & -1.50 & 0.89 & -1.00 & 1.15 & -1.08 & 1.05 & 0.15 & 1.10 \\
\hline 16 & -0.87 & 0.88 & -1.00 & 1.33 & -1.14 & 1.01 & -0.65 & 1.09 \\
\hline 17 & 0.87 & 1.02 & 1.10 & 0.74 & 0.70 & 0.78 & 1.07 & 0.80 \\
\hline 18 & 1.12 & 0.50 & 0.90 & 0.74 & 0.48 & 0.92 & 0.77 & 0.80 \\
\hline 19 & -0.37 & 1.15 & -0.22 & 1.47 & -0.89 & 1.15 & -0.61 & 1.01 \\
\hline
\end{tabular}

Very $\operatorname{good}=2 \quad$ Good $=1 \quad$ Borderline $=0 \quad$ Needs work=-1 $\quad$ Poor $=-2$

In the present study, in-group score differences were expected in the two groups of EFL learners. However, the variability found among professors and native speakers deserves special attention. Teachers and native speakers are supposed to provide baseline data for this study because the first group is specifically trained in the teaching and evaluating of grammatical and pragmatic aspects of the language. In addition, although the second group does not have that formal training, all the students are native speakers of the language and, consequently, are expected to at least have intuitions as to what is correct and what is appropriate. However, at times these two groups of subjects either do not agree $100 \%$ on what constitutes a grammatical or pragmatic violation, or they rate the seriousness of the problem differently.

Discrepancies might be due to the limitations of the instrument, or to lack of attention while completing the judgment task. However, the most likely explanation is that the professors and the native speakers have varying degrees of tolerance of violations.

As was mentioned earlier, discrepancies in scores among groups were found. In order to determine the nature of those discrepancies, score differences between groups were calculated. Table 4 presents the results for accuracy. To facilitate possible comparisons, differences are expressed in absolute values.

Table 4 reveals some differences between professors and native speakers. The most significant one resides in the accuracy scores of message 12 below. While 3 professors 
REVISTA DE FILOLOGÍA Y LINGÜÍSTICA

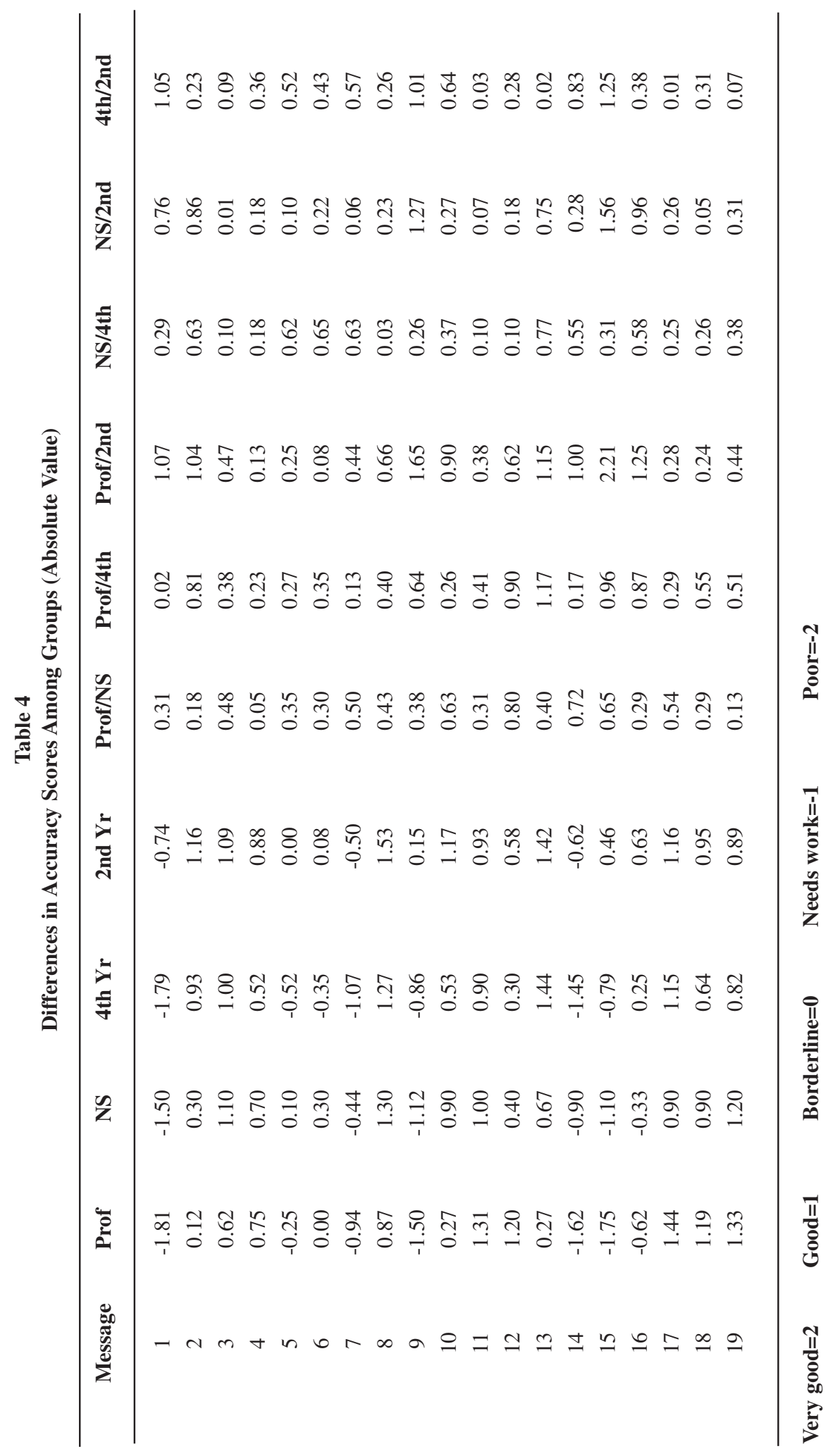


considered it "very good" and 13 rated it as "good" — an accurate message overall—none of the US students rated it as "very good," 5 as "good," 4 as "borderline" and 1 as "needs work."

Message 12
Dear (female professor's full name):
(Female professor's first name) has our grades ready. Could you please sign the "constancias"?
Thank you. Please leave them in the Secretaría so we can pick them up before you leave. Thank
you very much.
(First name of two students)
(Smiley face)

These differences are perhaps due to the fact that teachers tend to have more realistic expectations as to what learners in an EFL situation can reasonably acquire in a given period of time. However, another likely explanation is that since the US students are not familiar with the situation, they may not understand the message: the students writing the note need a signed document from this professor to take to the department office for graduation and, since the instructor is apparently leaving the country for the Christmas break, they are trying to arrange a solution to the problem. Another possibility is that the US students do not approve of the use of code switching.

The comparison of accuracy scores of professors and fourth year students shows 11 similar scores. (For the purposes of the present study, a difference of less than 0.40 will be considered a similar rating.) However, the professors gave higher scores to 3 messages, and the students to 5 . The comparison of the scores of the professors and second year students indicates that only 6 scores were similar, the professors gave higher scores to 2 messages, and the students to 11 . These data seem to indicate that second year students are still not able to detect some grammatical problems, especially given that the differences are considerable.

Moreover, comparing the accuracy scores of US and fourth year students shows that they rated 12 messages similarly; the US students rated 4 messages higher while the fourth year students only 3 . When the scores of the US and the second year students are compared, it is revealed that they rated 13 messages similarly, and that the second year students gave higher scores to the remaining 6 .

Table 5 presents the differences in appropriateness scores.

Table 5 shows that professors and native speakers rated appropriateness somewhat differently. They gave similar scores to 11 messages; however, professors rated 2 higher and native speakers 6 . There are also differences in the scores of professors and fourth year students. They rated 10 of them similarly, but professors rated 6 of them higher, and fourth year students 3. Differences are more evident when comparing professors' scores with those of second year students. They rated 10 messages similarly while professors assigned higher scores to 2 , and second year students rating 7 higher.

Native speakers and students showed differences as well. The US and the fourth year students gave similar scores to 11 messages; the native speakers rated 5 messages higher, and the fourth year students 3 . US and second year students agreed on the appropriateness scores given to 14 messages. However, the second year students assigned higher scores to 5 messages. 


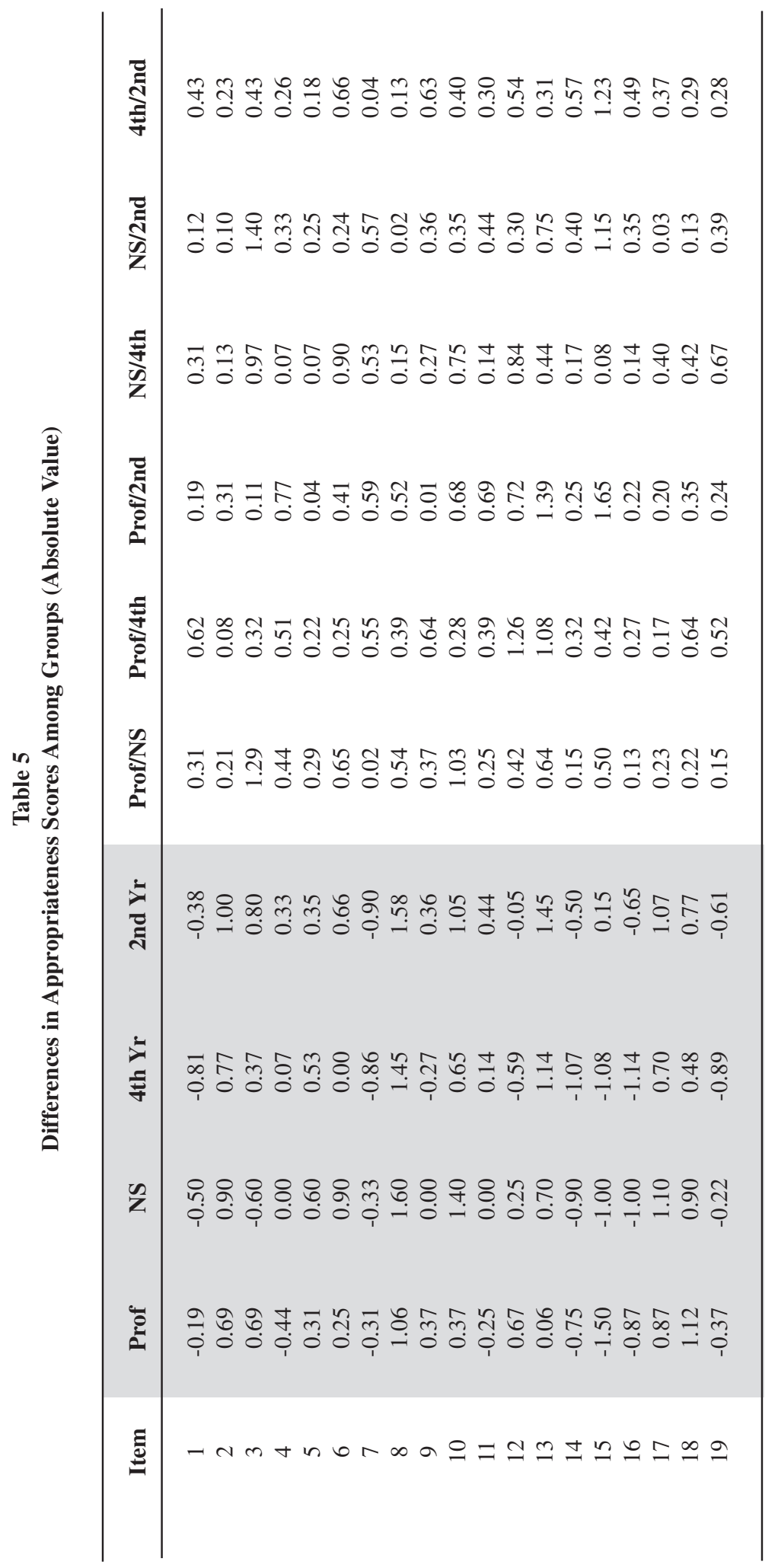


However, there are also similarities across the board. A perfect example is message 8 , which is transcribed below.

\section{Message 8}

Mrs. (professor's last name):

I could not bring the journal on Monday because I spent the whole morning and part of the afternoon in the hospital. I apologize for not calling a classmate in order to inform you.

(Student's name)

(Student's ID number)

This message received the highest accuracy score from US, fourth, and second year students. Professors gave it the second highest mark. As to appropriateness, it also received the highest scores from all the student groups and the sixth highest from the professors. It is necessary to explain that the professors' mean score was good (0.87). Except for a spelling mistake, this message is accurate. This readily explains the accuracy scores. As to appropriateness, the message does not suffer from the problems that subjects most frequently object to. Participants insisted that messages should be succinct and direct, that they should not include irrelevant details that were of no interest to the professor or that had been used to arouse pity or to manipulate, that the students should actually apologize, that they should use politeness formulas to express deference, that they should use the professor's title and full name, and that they should sign the message using their full name.

Another important issue to consider is whether the groups are able to judge the accuracy and the appropriateness of a given message independently, that is, whether they can see that there is a possibility for a grammatically perfect message to be very inappropriate or for a message that has many serious language problems to be appropriate. Table 6 presents the differences in scores of the two components of communicative competence. They are ranked in ascending order to highlight the most striking differences perceived by the four groups.

The most interesting information in Table 6 is that while the professors and the native speakers judged the degree of accuracy and the degree of appropriateness of 5 messages as quite different-more than 1 point variance - the fourth year students saw that kind of difference in 3 messages and the second year students only in 2. Table 7 summarizes those differences.

The data in Table 7 suggest that fourth year students, and to an even higher extent the students in second year, tend to associate the grammaticality they perceive in a message with appropriateness and vice versa. Another issue to consider is whether a person's honest desire to make a request or to apologize appropriately can be obscured by his or her lack of linguistic competence. Therefore, the appropriateness of the message can sometimes be difficult to gauge. 


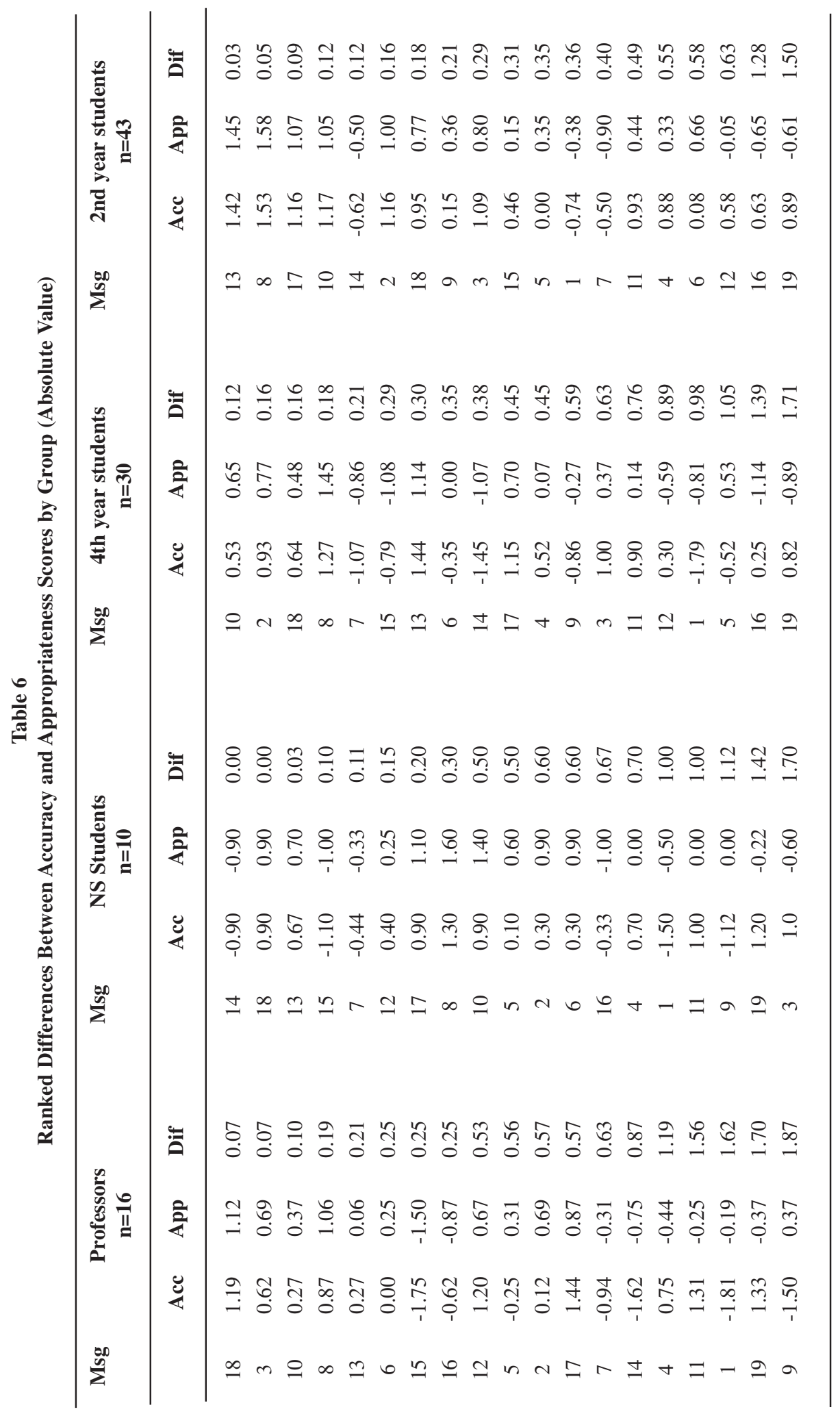


Table 7

Number of Messages in Each Interval

\begin{tabular}{ccccc}
\hline Intervals & Professors & Native Speakers & 4th year students & 2nd year students \\
\hline 0.00 to 0.49 & 8 & 8 & 11 & 14 \\
0.50 to 0.99 & 6 & 6 & 5 & 3 \\
1.00 to 1.87 & 5 & 5 & 3 & 2 \\
\hline
\end{tabular}

\subsection{When rating the messages, do the EFL learners justify their scores by using arguments similar to those given by the US students and the EFL teachers?}

Subjects justified their choices in different ways, making the comparison tricky. However, some interesting generalizations can be made. First, second year students seem to lack the metalanguage necessary to discuss accuracy or appropriateness problems. Most of them justified their choices in Spanish, and their comments were rather short. For example, they often used adjectives such as "informal," "disrespectful" or "impolite" as the sole justification. Occasionally, they provided no justification whatsoever, or they wrote short phrases that provided no information, such as "Some reasons." Finally, this was the only group where one of the subjects rated the appropriateness of all the messages as either good or very good.

The judgments of the fourth year students were more sophisticated. First of all, fewer comments were written in Spanish. In general terms, they were longer and more elaborate, and students occasionally used metalanguage to refer to accuracy and, in a few cases, to appropriateness issues. For example, a student remarked that the author of the message should 'Use language like 'I apologize,' ' thank you for understanding,' 'sincerely' etc. You need a better explanation. This is a pathetic excuse." However, a few students used comments such as "terrible grammar, terrible organization" to justify an appropriateness rating, thus revealing his or her inability to separate accuracy from appropriateness. In addition, one of the students made the following comment, "The whole structure screws up the message." One wonders whether the student is aware of the fact that he or she is using slang and that this might be judged as inappropriate in the context of a classroom activity. Another student, in order to justify his or her rating of the appropriateness of a message as poor, wrote "Without words!" (sic)

The US college students were unable to understand some of the messages. Unlike the other participants, most of them cannot easily anticipate negative transfer errors, which makes inference of intended meaning easier. After rating the appropriateness of a message as poor, a student wrote, "Unable to determine appropriateness due to the inadequate grammatical structure." Another student was baffled by the sentence "I wait excuse me." In addition, some of them repeatedly referred to norms in a US university, that is, their background knowledge. A student stated "In the US you use professor's last name unless she has ok first name usage. Most US students use professor." Another student justified his score by saying, "It's appropriate, I guess, but I wouldn't say it that way." This comment probably means that although the language is polite, the message lacks mitigators.

Most of the professors' justifications were detailed, and they used metalanguage frequently. For example, a professor wrote, "Despite the use of the modal 'would' 
conveying politeness and hope, the message's content is vague enough to be frustrating to the receiver." Others, however, were short and simply mentioned the item that was inaccurate or inappropriate but did not offer any explanations. For instance, a professor wrote "pushy" and another "tenses." As to the use of first names to address a professor, 56\% of the instructors objected to the practice. Two of them added that it was especially inappropriate in writing.

Another important difference between the comments made by professors and those made by the rest of the subjects is that professors more consistently associated the choice of certain grammatical forms with the acts of requesting or apologizing. For instance, they insisted on the use of modal auxiliaries and questions to mitigate the imposition of a request. A professor wrote, "Needs to soften request because it sounds like an order. Choice of modal auxiliaries." They also mentioned the inappropriateness of imperative forms in such contexts. Another professor stated that the learner needed "language formulas for apologies."

\subsection{Do EFL learners misidentify errors or violations?}

The only "error" identified by students that is not actually an error is the use of "dear" before a professor's name. Second year students made comments like "Dear, truly yours! It is a professor not a lover!" (sic) and a fourth year student claimed that "Dear is informal." Obviously, these students have had little or no training in letter writing and are confused because of the difference between "querido" and "estimado" in Spanish. Moreover, this misconception must be widespread since one of the professors also identified it as a violation.

This particular language deficiency should be a warning to the writing instructors at the School of Modern Languages. Changes in programs need to be made soon to include the writing of documents such as business letters, memos, and resumes, which are important in the business world where many of them aspire to work. The study of cross-cultural pragmatics must be emphasized. As Boxer (2002: 151) points out, "individuals from two communities carry out their interactions (whether spoken or written) according to their own rules or norms, often resulting in a clash in expectations and, ultimately, misperceptions about the other group."

\section{Pedagogical Implications}

Nelson (2002: 164) claims that it is difficult to know whether pragmatic failure results from L1 transfer or from other source unless the teacher or researcher knows the strategies of both the L1 and the L2. Kim (2002:333) adds that because many EFL teachers have learned English as a foreign language themselves, they may not have had many opportunities to develop their pragmatic knowledge and skills fully. Therefore, their ability to provide appropriate learning experiences may also be rather limited. In the School of Modern Languages, however, professors are in an advantageous position because all of them are bilingual and, in varying degrees, bicultural. Consequently, they should be well prepared to teach the pragmatic rules of English. However, as Boxer (2002: 151) has pointed out "It is only in the past two decades that any effort at all has been exerted to make learners aware of pragmatic differences between L1 and L2," and the data in the present study suggest that this might have been the case at the University of Costa Rica. 
Another question to ponder is whether we are aware of the fact that there are many types of native speakers and that pragmatic norms may change from community to community. Cem Alptekin (2002: 57) questions "the validity of the pedagogic model based on the native speaker-based notion of communicative competence. With its standardized native speaker norms, the model is found to be utopian, unrealistic and constraining in relation to English as an international language." Because of the close relationship between Costa Rica and the United States and the presence of US companies that hire many of our graduates, it seems obvious that there is a need to study and teach the norms prevalent in that country.

A crucial concern needs to be addressed: how to teach pragmatics. The results of the present investigation suggest that perhaps the activities and materials used in our classrooms do not provide learners with enough pragmatic input for target-like grammatical and pragmatic judgments. Therefore, we must take a more proactive approach. Bardovi-Harlig et al. (1991:5) point out that "the real responsibility of the classroom teacher is not to instruct students specifically in the intricacies of complimenting, direction-giving, or closing a conversation: rather, it is to make students more aware that pragmatic functions exist in language, specifically in discourse, in order that they may be more aware of these functions as learners." They propose pragmatically centered activities such as having learners examine a language function in their own language and culture. They also feel that teachers should invite native speakers to the class in order to offer natural models. They suggest more structured approaches where students act out and compare felicitous and infelicitous speech acts in textbook dialogues. Learners can also reconstruct speech acts from individual turns in a conversation, participate in role-play activities, and collect data focusing on specific speech acts.

However, more explicit teaching might also benefit the students. For example, if instructors approach the teaching of grammar from a broad perspective that includes not only form (morphosyntactic and lexical patters as well as phonemic and graphemic patterns) but also meaning (lexical and grammatical) and use (social context, linguistic discourse context and presuppositions about context) as Larsen-Freeman (2001: 252) has proposed, we will be in a better position to deal with accuracy and appropriateness issues simultaneously. LarsenFreeman (2001:265) adds that the form, meaning and use framework can help teachers assess their own gaps in their knowledge of English. For example, if they are to teach modal auxiliaries, one of the weakest areas in the present study, and the instructor cannot figure out the three dimensions, that should be an invitation to consult a reference grammar or to discuss the issue with colleagues, which are good alternatives for professional development.

\section{Bibliography}

Alptekin, Cem. 2002. "Towards intercultural communicative competence in ELT". ELT Journal. 56 (1): 57-64.

Bardovi-Harlig, Kathleen et al. 1991. "Developing pragmatic awareness: Closing the conversation”. ELT Journal. 45 (1): 4-15.

Bardovi-Harlig, Kathleen and Zoltán Dörnyei. 1998. "Do language learners recognize pragmatic violations? Pragmatic versus grammatical awareness in instructed L2 learning". TESOL Quarterly. 32: 233-62. 
Boxer, Diana. 2002. "Discourse issues in cross-cultural pragmatics". Annual Review of Applied Linguistics. 22: 150-167.

Canale, Michael. 1983. "From communicative competence to communicative language pedagogy". En: J. C. Richards and R. W. Schmidt (eds.), 2-27.

Canale, Michael and Merrill Swain. 1980. "Theoretical bases of communicative approaches to second language teaching and testing". Applied Linguistics. 1: 1-47.

Celce-Murcia, Marianne (Ed.). 2002. Teaching English as a second or foreign language. Tercera edición. Boston: Heinle \& Heinle.

Hasbún, Leyla. 2001. "Assessment of grammatical errors and pragmatic failure". Filología y Linguística. 27 (1): 249-263.

Kasper, Gabriele. 2001. "Four perspectives on L2 pragmatic development". Applied Linguistics. 22 (4): 502-30.

Kasper, Gabriele y M. Dahl. 1991. "Research methods in interlanguage pragmatics". Studies in Second Language Acquisition. 13: 215-247.

Kasper, Gabriele y Richard Schmidt. 1996. "Developmental issues in interlanguage pragmatics". Studies in Second Language Acquisition. 18: 149-69.

Kim, Daejin y Joan Kelly Hall. 2002. "The role of an interactive book reading program in the development of second language pragmatic competence". The Modern Language Journal.

Larsen-Freeman, Diane. 2001. "Teaching grammar”. En Marianne Celce-Murcia (ed.), 251266.

Nelson, Gayle et al. 2002. "Cross-cultural pragmatics: Strategy use in Egyptian Arabic and American English refusal”. Applied Linguistics. 23 (2): 163-189.

Richards, Jack C. y R. I. Schmidt (eds.). 1983. Language and Communication. London: Longman. 